\title{
Furniture Dimensions in the Library Reading Area at University of Trunojoyo Madura
}

\author{
Mahrus K. Umami ${ }^{1}$, Halimatus Zahroh, Imron Kuswandi, Teguh Prasetyo, Mirza Pramudia \\ Department of Industrial \& Mechanical Engineering \\ University of Trunojoyo Madura \\ Bangkalan, Indonesia \\ ${ }^{1}$ Mahrus.umami@trunojoyo.ac.id
}

\begin{abstract}
The compatibility between the dimensions of furniture and users' body is crucial in keeping the users' performance. The objective of this study is to identify whether the furniture dimensions in the library reading area at University of Trunojoyo Madura (UTM) are appropriate/inappropriate to the students' anthropometry and to find a recommendation for appropriate dimensions for designing library furniture. The current study was begun by measuring the furniture dimensions and the students' anthropometry. The evaluation was done by following methods adapted from previous studies that determine the furniture dimensions based on the anthropometric and ergonomic principles. The compatibility criterion was determined by considering the relationship between the furniture dimensions, the students' anthropometry and assumption(s) regarding what they wear and their behaviors during they are in the reading area. The finding of this study showed the mismatch between the students' anthropometry participated in the measurements and the furniture dimensions. Another important finding was that this study provided/offered a recommendation that was suitable dimensions for designing library furniture at UTM.
\end{abstract}

Keywords - furniture dimensions; anthropometry; chair; desk; bookcase

\section{INTRODUCTION}

Students spend their time in a sitting position to do their lecture work in the classroom, library, studying room and some other possible places. Considering the duration spent in the sitting position, the match between the seat and the students' anthropometry is very important. This is because the mismatch between the furniture dimensions and the user anthropometry could potentially lead to negative implication such as learning comfort [1], fatigue occurrence [2], and musculoskeletal disorders [3][4][5].

Few approaches have been developed in evaluating the furniture dimensions and the users' anthropometry. One of the evaluation methods is comparing the users' anthropometry and the relevant furniture dimensions. A general principle in designing a product, i.e. (1) design for average dimensions, (2) design for extreme dimensions and (3) design for a specific range dimension, was also possible to use in a furniture evaluation[6]. In addition, it also crucial to consider the users' mental characteristics and behaviors in using the furniture. Each user has a specific need and obstacle when he/she was sitting on a chair. For example, individuals with upper back and neck problem probably like chair with the upper edge of the backrest tapers and narrows in order that they could get more freedom of motion. Overall, an approach used by [7] is considerable and practicable. The proposed equations that were developed and adapted from previous relevant studies can help other researchers in evaluating the furniture design.

Students are a unique occupational group since their stage of development influences some aspects of their humanmachine-environment system [4]. Regarding the furniture design for the students, many studies have been conducted to evaluate a potential incompatibility between the dimensions of furniture and students' body [8][9].

Few studies performed in various university/college of different country confirmed the incompatibility between the dimensions of furniture and the students' body [9] [10][11]. Similar findings also occurred in few observations on the school furniture [12][13][14][15]. Considering the lack of anthropometric data for the Indonesian population and the existent of various ethnics in this nation, findings of those studies were also possible to occur in Indonesia. Specifically, since there was no detail information about the furniture dimensions and their relevant anthropometry of students at UTM, it was possible to say that the current study is very important to solve the question whether the furniture in the library reading area match to the students' anthropometry or not.

Drawing from the background above, the objective of this study is to analyze the compatibility between the furniture dimensions and the students' body. Considering the case in the library reading area at the University of Trunojoyo Madura, it specifically aims to find a recommendation for appropriate dimensions for designing library furniture.

\section{METHODS}

In order to address the research problem defined above, this study was conducted in a few steps. First, an observation was done to identify the furniture types available in the library reading area at UTM. The second step was measuring the 
anthropometry of students which was relevant to furniture dimensions. The third step was comparing the dimension of chair, desk, and bookcase to the relevant students' anthropometry. The last step was choosing and modifying equations used to determine the suitable furniture design from the ergonomic perspective.

Four types of chair and two types of desk available in the library reading area were measured. A type of bookcase was also observed and compared to the relevant student anthropometry.

Students who frequently come and occupy the library reading area were recruited to participate in this study voluntarily. There are no specific requirements for the students to participate in this study, except they must have a normal body stature and frequently come to the library reading area.

Furniture dimensions included in the measurement were selected by considering their relationship with the relevant students' body dimensions (TABLE I). The measurements of all dimensions on the furniture and the students' body were done using a measuring tape.

The furniture dimensions are defined as follow:

- Seat plane height (SPH): the distance measured from the seat plane to the floor

- Desk height (DH): the distance measured from the top of the desk to the floor

- Upper shelf height (USH): the distance measured from the upper shelf plane to the floor.

TABLE

FURNITURE DIMENSIONS AND RELEVANT USERS’ BODY DIMENSIONS

\begin{tabular}{|l|l|l|}
\hline Furniture & \multicolumn{1}{|c|}{ Furniture Dimension } & \multicolumn{1}{c|}{ Body dimension } \\
\hline \multirow{3}{*}{ Chairs } & Seat plane height (SPH) & Popliteal height (PH) \\
\cline { 2 - 3 } & Seat plane depth (SPD) & Buttock-popliteal length (BPL) \\
\cline { 2 - 3 } & Seat plane width (SPW) & Hip width (HW) \\
\hline Desks & Desk height (DH) & Elbow height (sitting) (EHS) \\
\hline Bookcases & Upper shelf height (USH) & Vertical grip reach (VGR) \\
\hline
\end{tabular}

a. Adapted from [7]

Four body dimensions and their definitions were adopted from [7], namely:

- Stature $(\mathrm{S})$ : defined as the body height, the distance measured from the top of head to the floor and taken with the subject in the standing posture with looping straight ahead (Frankfort plane).

- Popliteal Height (PH): the distance between the floor or footrest and the back surface of the knee (popliteal surface), measured with $90^{\circ}$ knee flexion.

- Buttock-Popliteal Length (BPL): the distance measured from the back surface of the buttock to the popliteal surface and taken with a $90^{\circ}$ angle of knee flexion.
- Hip Width (HW): the distance measured from the outer side of the left hip to the outer side of the right hip in the sitting position.

Three other dimensions were defined as follow:

- Elbow Height (sitting) (EHS): the distance measured from the lower point of the elbow tip (olecranon) to the subject's seated plane, measured with a $90^{\circ}$ angle elbow flexion.

- Lumbar Height (sitting) (LHS): the distance between the highest point of the lumbar to the subject's seated plane.

- Vertical Grip Reach (VGR): the maximum vertical distance between the floor and the hand, measured with the subject standing upright and raising his hand in a gripping position.
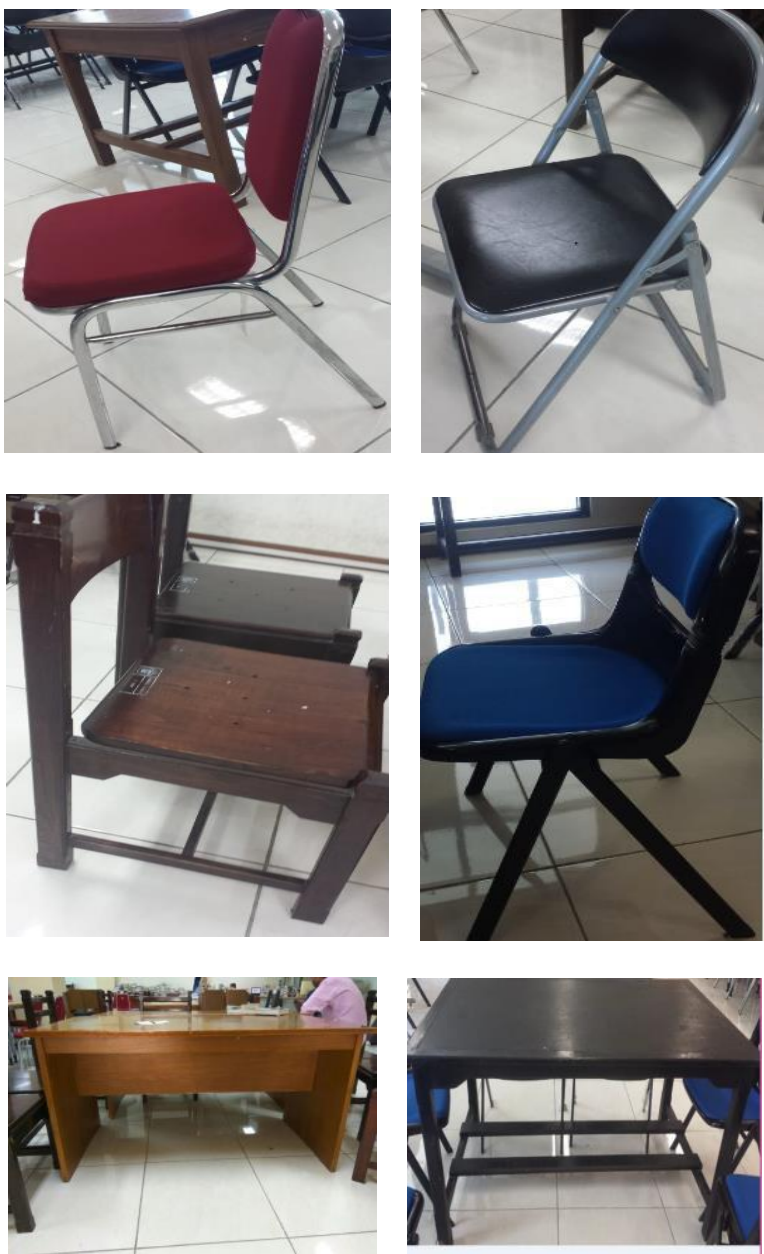

Fig. 1. Types of chairs and desks analyzed. 


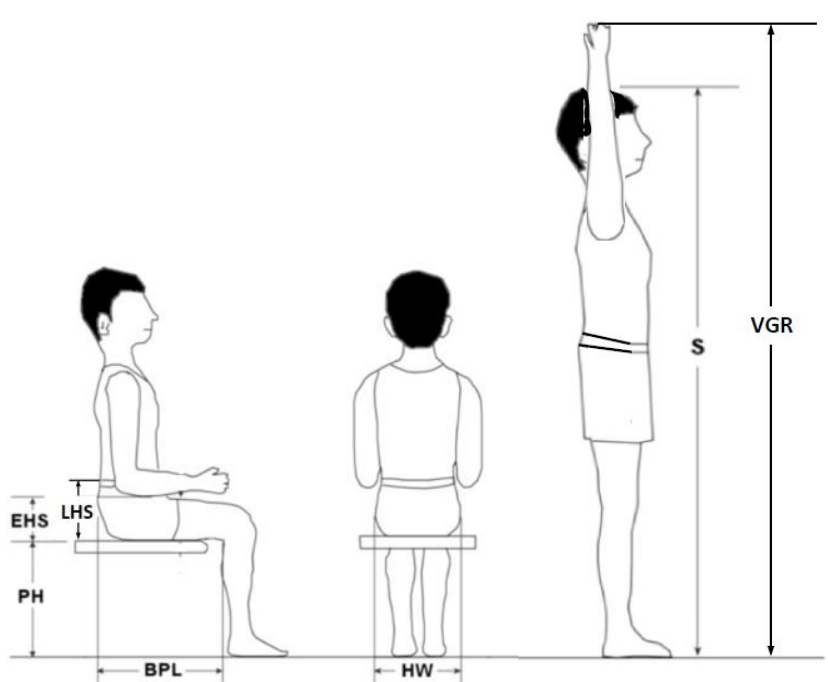

Fig. 2. Body dimensions measured in the current study (Adapted from [2]).

The evaluation was done by following methods proposed by [2] that determine the furniture dimensions based on the anthropometric and ergonomic theories. The compatibility criterion was determined by considering the relationship between the furniture dimensions, the students' anthropometry and assumption(s) regarding the students wears and behaviors during they are in the reading area. Accordingly, six equations proposed by [7] and [16] were applied in the analyses. In addition, an equation was developed to represent the relationship between the USH and the VGR.

\section{A. Seat plane height vs. Popliteal height}

Equation (1) developed by considering an evidence showing that SPH should be lower than the PH, their difference should not be more than 4 centimeters. Since it is assumed that all students wear their shoes in the reading area, the shoe sole thickness of 3 centimeters was added in this equation [7]. To accommodate more users, the $5^{\text {th }}$ percentile of the $\mathrm{PH}$ should be considered in the design.

$$
(\mathrm{PH}+3) \cos 30^{\circ} \leq \mathrm{SPH} \leq(\mathrm{PH}+3) \cos 5^{\circ}
$$

\section{B. Seat plane (depth) vs. Buttock-popliteal length}

Numerous studies have recommended that the SPD should be designed for the $5^{\text {th }}$ percentiles of BPL distribution [4]. Besides, the SPD should be longer than the BPL in order that it is possible to support the thigh well. The match criterion was defined as (2) [12].

$$
0.8 \mathrm{BPL} \leq \mathrm{SPD} \leq 0.95 \mathrm{BPL}
$$

\section{Seat plane width vs. Hip width}

The SPW should be designed wider than the HW in order that users can sit on the chair comfortably [6]. It must consider the $95^{\text {th }}$ percentile, the largest hip width.
SPW > HW

\section{Lower edge of the backrest vs. Lumbar height (sitting)}

The LEB should be designed lower than the LHS in order that the backrest can support the back of the user properly [6]. It is possible to consider the $5^{\text {th }}$ percentile, the smallest lumbar height (sitting).

$$
\text { LEB } \leq \text { LHS }
$$

\section{E. Desk height vs. Elbow height}

The desktop should be designed parallel with the elbow. Other recommendation showed that the DH should be $3-5 \mathrm{~cm}$ higher than the EH [3][4]. Since the DH was a distance between the desktop and the floor, in this study the DH was determined by using (5).

$$
\mathrm{EHS}+\mathrm{PH}+3 \leq \mathrm{DH} \leq \mathrm{EHS}+\mathrm{PH}+8
$$

\section{F. Upper shelf height vs. Vertical grip reach}

The USH was determined with an assumption that the book size is $30 \mathrm{~cm}$ high. In order that the students could reach dan take the desired book easily, the USH should be equal to or lower than the VGR.

$$
\mathrm{USH} \leq \mathrm{VGR}-30
$$

\section{RESULTS AND DISCUSSION}

As mentioned in Section II, firstly this study measured the furniture dimensions in the reading area of the main library at the University of Trunojoyo Madura. It then compares them to the students' anthropometry. Seventy-seven students (47 females) aged in the range of 18 and 24 years old involved in the measurement. The furniture dimensions and the students' anthropometric data were described below.

\section{A. Furniture dimensions}

There are four types of chairs, two types of desks and a type of bookcase in the library reading area at UTM. The dimensions of the chairs were varied, as shown in TABLE II. It also possible to see the relevant desks and bookcase dimensions in TABLE III.

TABLE II. CHAIR DIMENSIONS

\begin{tabular}{|l|l|l|l|l|l|}
\hline \multirow{2}{*}{ No } & \multirow{2}{*}{ Dimension } & \multicolumn{4}{|c|}{ Measure (mm) } \\
\cline { 3 - 6 } & & Chair 1 & Chair 2 & Chair 3 & Chair 4 \\
\hline 1 & SPH & 44 & 42 & 47 & 47 \\
\hline 2 & SPD & 48 & 38 & 52 & 44 \\
\hline 3 & SPW & 46 & 48 & 50 & 41 \\
\hline 4 & LEB & 28 & 17 & 28 & 8 \\
\hline
\end{tabular}


TABLE III. DESK AND BOOKCASE DIMENSIONS

\begin{tabular}{|l|l|l|}
\hline No. & \multicolumn{1}{|c|}{ Dimension } & Measure $(\mathbf{m m})$ \\
\hline 1 & DH-1 & 68 \\
\hline 2 & DH-2 & 70 \\
\hline 3 & USH & 165 \\
\hline
\end{tabular}

\section{B. Students' body dimensions}

The descriptive statistics of the six body dimensions of students participated in the measurements are indicated in TABLE IV.

TABLE IV. SELECTED ANTHROPOMETRY RELEVANT TO FURNITURE DIMENSIONS

\begin{tabular}{|l|l|l|l|l|l|}
\hline No & Dimension & \multicolumn{1}{|c|}{$\begin{array}{c}\text { Mean (SD) } \\
(\mathbf{m m})\end{array}$} & $\begin{array}{c}\mathbf{5 \%} \text { tile } \\
(\mathbf{m m})\end{array}$ & $\begin{array}{c}\mathbf{5 0 \%} \text { tile } \\
(\mathbf{m m})\end{array}$ & $\begin{array}{c}\text { 95\% tile } \\
(\mathbf{m m})\end{array}$ \\
\hline 1 & PH & $42.6(2.7)$ & 38,0 & 43,0 & 46,2 \\
\hline 2 & BPL & $45.9(3.7)$ & 40,0 & 45,0 & 51,2 \\
\hline 3 & HW & $33.9(4.1)$ & 30,0 & 33,0 & 42,2 \\
\hline 4 & LHS & $22.9(3.3)$ & 20,0 & 23,0 & 25,0 \\
\hline 5 & EHS & $26.1(3.3)$ & 21,0 & 26,0 & 32,0 \\
\hline 6 & VGR & $192.8(10.8)$ & 172,6 & 193,0 & 210,2 \\
\hline
\end{tabular}

\section{Incompatibility between the body measures and the furniture dimensions}

This comparison was done between the present furniture dimensions (TABLE II and III) and the students' body dimensions (TABLE IV). The compatibilities/ incompatibilities between the corresponding dimensions were presented below.

Seat plane height is the most important dimension in designing a chair [7]. The result of analyses showed that all of the chairs were too high for $6.5 \%$ of students. Chair 3 and chair 4 were only appropriate for $20.1 \%$ of the students. Chair 1 is appropriate for $66.2 \%$ of the students involved in this study. Most of the students $(74 \%)$ are possible to use Chair 2 comfortably. From the SPH perspective, it should be noted that chair 3 and chair 4 too high.

Comparison of seat plane depth between the anthropometric measures and their relevant chair dimensions showed that chair 2 was only possible for $7.8 \%$ of the students. The current study found that $64.9 \%$ of the students can use chair 4 . It should be emphasized that $11.7 \%$ of the students are inappropriate with all chairs since the SPD is shorter than the relevant anthropometric dimension. It means the students' thigh was not supported adequately during they were sitting on the chair [6].

The result of this study also found all students are possible to use all chairs except chair 4 . The SPW of chair 4 is inappropriate for $7.8 \%$ of students participated in the current study since their HW are larger than the SPW. In general, regarding the SPW, most of the students are possible to sit on the chair comfortably.
Desk height which also plays an important role in keeping the students' comfort was appropriate for $90 \%$ of the students. The desks 1 (DH-1) is too high for $5 \%$ of the students, while the desk 2 (DH-2) is too high for $10 \%$ of the students. The higher desk will make the students raising up their upper arm too much, and it can lead to some musculoskeletal disorders [6].

Considering the USH and the VGR, this study found that the USH is too high for $48 \%$ of the students. Assuming the book dimension is $30 \mathrm{~cm}$ high, $52 \%$ of the students can take a book on the bookcase easily. The first group of the students have a lower grip reach than the second group and would be possibly difficult to reach a book on the shelf.

\section{Recommended furniture dimensions}

The results of this study showed that generally the furniture dimensions do not match with the anthropometry of students participated in the current study. Although the number of students included in the measurements is too small, the results are possible to describe a fact that the recommended dimensions are needed for designing the library furniture. TABLE V shows the recommended dimensions that are able to consider in the design. This recommendation was based on the anthropometric data and the relevant equations in Section II.

\section{TABLE V. RECOMMENDED DIMENSIONS FOR THE LIBRARY FURNITURE}

\begin{tabular}{|l|l|l|}
\hline No. & \multicolumn{1}{|c|}{ Dimension } & \multicolumn{1}{c|}{ Measure $(\mathbf{m m})$} \\
\hline 1 & SPH & $35.5-40.8$ \\
\hline 2 & SPD & $32.0-38.0$ \\
\hline 3 & SPW & $>42.2$ \\
\hline 4 & LEB & $<20.0$ \\
\hline 5 & DH & $56.6-64.8$ \\
\hline 6 & USH & $<142.6$ \\
\hline
\end{tabular}

\section{CONCLUSION}

This study is aimed to analyze the compatibility between the students' body and the furniture in the reading area at the University of Trunojoyo Madura and to find a recommendation for appropriate dimensions for designing library furniture. In general, this study found the mismatch between the students' anthropometry participated in the measurements and the furniture dimensions. Although the number of students participated in this study is too small, it is possible to describe a need for the recommended dimensions in designing the library furniture at UTM. This study also provided a recommendation that was suitable dimensions for designing library furniture at UTM.

\section{ACKNOWLEDGMENT}

This study was done by supports of the Department of Industrial and Mechanical Engineering, University of Trunojoyo Madura. Authors also thank all of the students at the Ergonomic and Work System Design Research Group who 
have participated and given some assistance during the furniture and students' anthropometric measurements.

\section{REFERENCES}

[1] D. S. Hira, "An ergonomic appraisal of educational desks," Ergonomics, vol. 23, no. 3, pp. 213-221, 1980.

[2] A. I. Musa, S. O. Ismaila, S. B. Adejuyigbe, and O. D. Akinyemi, "Ergoeffects of designed school furniture and sitting positions on students' behaviour and musculo-skeletal disorder in Nigerian tertiary institutions," Manag. Sci. Lett., 2011.

[3] C. S. Savanur, C. R. Altekar, and A. De, "Lack of conformity between Indian classroom furniture and student dimensions: Proposed future seat/table dimensions," Ergonomics, vol. 50, no. 10, pp. 1612-1625, 2007.

[4] S. Milanese and K. Grimmer, "School furniture and the user population: An anthropometric perspective," Ergonomics, 2004.

[5] A. I. Musa and S. O. Ismaila, "Student anthropometric data and furniture mismatches in selected institutions in Abeokuta, Ogun State, Nigeria," Theor. Issues Ergon. Sci., 2014.

[6] S. Pheasant and C. M. Haslegrave, "Bodyspace: Anthropometry, Ergonomics, and the Design of Work," Health San Francisco. 2006.

[7] H. I. Castellucci, P. M. Arezes, and C. A. Viviani, "Mismatch between classroom furniture and anthropometric measures in Chilean schools," Appl. Ergon., 2010.

[8] E. Kahya, "Evaluation of the classroom furniture for university students," vol. 26, no. 1, pp. 20-29, 2018.

[9] A. S. M. Hoque, M. S. Parvez, P. K. Halder, and T. Szecsi, "Ergonomic design of classroom furniture for university students of Bangladesh," $J$. Ind. Prod. Eng., vol. 31, no. 5, pp. 239-252, 2014.

[10] J. V Reddy, "Evaluation of Library Furniture and Anthropometric Characteristics of St. Mary's Students for Ergonomics Design of Table and Chair," Int. J. Res. Stud. Sci. Eng. Technol., vol. 2, no. 5, pp. 27-32, 2015.

[11] A. S. Castilho, C. De Cássia A. Leme, and R. S. Padula, "Analysis of the suitability of furniture university-Anthropometric characteristics of user," in Work, 2012.

[12] C. Parcells, M. Stommel, and R. P. Hubbard, "Mismatch of classroom furniture and student body dimensions: Empirical findings and health implications," Journal of Adolescent Health. 1999.

[13] Z. Z. Afzan, S. A. Hadi, B. T. Shamsul, H. Zailina, I. Nada, and A. R. S. Rahmah, "Mismatch between school furniture and anthropometric measures among primary school children in Mersing, Johor, Malaysia," in 2012 Southeast Asian Network of Ergonomics Societies Conference: Ergonomics Innovations Leveraging User Experience and Sustainability, SEANES 2012, 2012.

[14] A. A. Mohd Yusoff, I. Rasdi, A. S. Mahmoud Ben Hameid, and K. Karuppiah, "Mismatch between furniture dimension and anthropometric measures among primary school children in Putrajaya," Malaysian J. Public Heal. Med., vol. 1, no. Specialissue1, pp. 58-62, 2016.

[15] B. Biswas, F. B. Zahid, R. Ara, M. S. Parvez, and A. S. M. Hoque, "Mismatch between classroom furniture and anthropometric measurements of Bangladeshi primary school students," Int. Conf. Mech. Ind. Energy Eng. ,25-26 December 2014, pp. 1-6, 2014.

[16] H. I. Castellucci, P. M. Arezes, and J. F. M. Molenbroek, "Equations for defining the mismatch between students and school furniture: A systematic review," Int. J. Ind. Ergon., 2015.

[17] I. Castellucci, M. A. Gonçalves, and P. M. Arezes, "Ergonomic design of school furniture: Challenges for the Portuguese schools," Appl. Hum. Factors Ergon. Conf., p. CD--ROM, 2010. 